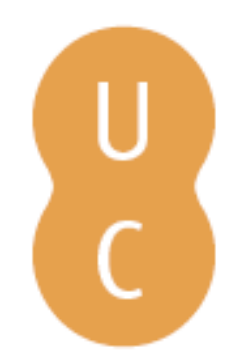

\title{
pompalina
}

\section{El Banquete de los Siete Sabios como tour de force escolar}
Autor(es):
González Equihua, Rodolfo
Publicado por: Imprensa da Universidade de Coimbra; Centro de Estudos Clássicos e Humanísticos

URL

persistente:

URI:http://hdl.handle.net/10316.2/32036

DOI:

DOI:http://dx.doi.org/10.14195/978-989-8281-17-3_43

Accessed : $\quad$ 26-Apr-2023 11:13:42

A navegação consulta e descarregamento dos títulos inseridos nas Bibliotecas Digitais UC Digitalis, UC Pombalina e UC Impactum, pressupõem a aceitação plena e sem reservas dos Termos e Condições de Uso destas Bibliotecas Digitais, disponíveis em https://digitalis.uc.pt/pt-pt/termos.

Conforme exposto nos referidos Termos e Condições de Uso, o descarregamento de títulos de acesso restrito requer uma licença válida de autorização devendo o utilizador aceder ao(s) documento(s) a partir de um endereço de IP da instituição detentora da supramencionada licença.

Ao utilizador é apenas permitido o descarregamento para uso pessoal, pelo que o emprego do(s) título(s) descarregado(s) para outro fim, designadamente comercial, carece de autorização do respetivo autor ou editor da obra.

Na medida em que todas as obras da UC Digitalis se encontram protegidas pelo Código do Direito de Autor e Direitos Conexos e demais legislação aplicável, toda a cópia, parcial ou total, deste documento, nos casos em que é legalmente admitida, deverá conter ou fazer-se acompanhar por este aviso.

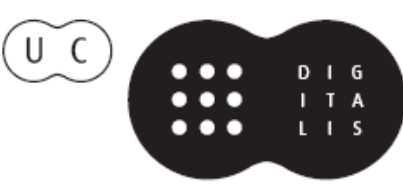




\section{Symposion and Philanthropia in Plutarch}

\section{José Ribeiro Ferreira, Delfim Leão Manuel Troster e Paula Barata Dias (eds.)}

IMPRENSA DA UNIVERSIDADE DE COIMBRA 


\title{
El BANQUete de Los Siete SABIos como touR DE Force ESCOLAR
}

\author{
Rodolfo González Equihua \\ Universidad de Salamanca
}

\begin{abstract}
The main issue of this contribution is to point out the genre of anecdote ( $\chi \rho \varepsilon i ́ \alpha)$ that Plutarch relates to the symposiac sphere according to the classification specified in progymnasmatic manuals, and to show how this rhetorical device works in the dialogization process of the symposium as a literary genre.
\end{abstract}

TOUR DE FORCE: exercice qui exige de la force. - PAR EXT. Action difficile accomplie avec une habilité remarquable. 2. Action ou moyen d'action qui suppose de l'adresse, de l'habileté, de la malice, de la ruse.

Le Nouveau Petit Robert (2004)

1. En 1928 Frank C. Babbitt calificó esta obra como un tour de force literario ${ }^{1}$. El empeño de Plutarco, desde plena época imperial, por recrear a un grupo legendario de legisladores y gobernantes de época arcaica en un género de época clásica ya sancionado por Platón y Jenofonte, exigía de su autor una

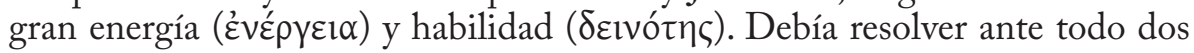
operaciones difíciles: la construcción escénica y revestir las conversaciones de sus personajes de naturalidad y encanto.

J. J. Reiske en el siglo XVIII y R. Volkmann ${ }^{2}$ en el XIX, con vistas al resultado y no a la intención, lamentan el abuso de anacronismos y la ausencia de un plan de conjunto, incluso el primero se permite afirmar que Tales de Mileto y los Sabios, por razones cronológicas, no habrían podido coincidir espacialmente ${ }^{3}$. Según esta objeción, a Plutarco el versátil escritor de las diversas formas literarias que conforman los Moralia, lo desacredita Plutarco el grave historiador de las programáticas Vidas paralelas. Quienes ejercieron la crítica interna del tratado ${ }^{4}$ concluyeron que nos encontrábamos ante un trabajo

${ }^{1}$ F. C. Babbitt, 1956, p. 346. La edición utilizada para este trabajo es la de J. Defrradas, Plutarque. Le Banquet des Septs Sages in J. Defradas et al. (eds.), 1985. La traducción citada es la de C. Morales Otal \& J. García López, Plutarco. Obras Morales y de Costumbres, II, Madrid, 1986.

${ }^{2}$ R. Volkmann, 1967.

${ }^{3}$ En D. A. Wyttenbach, 1821, p. 201 encontramos citado el curioso reparo de Reiske: "Non valde congruit historiae, quod hunc ficto nomine Niloxenum dictum Naucratitam facit. Nam Thaletis aetate, qui Cyro et Croeso aequalis uixit, Naucratis nondum erat, condita sub Inaro in Aegypto regnante et Artaxerxe in Perside circa Olymp. 90. teste Strabone p. 1153. Etiam aetates sapientium haud satis apte congruunt. Periander Solone est antiquior: mitto alium”. De ahí que WyTtenbach exclamara a continuación: "Hoc mibi est judicium docti hominis! si judicium dici potest temerarium dictum properanter scribentis."

${ }^{4}$ C. Meiners en su Geschichte des Ursprungs, Fortgangs und Verfalls der Wissenschaften in 
escolar $^{5}$ escrito por un sofista contemporáneo. Aquí escolar y sofístico, desde luego, son dos atributos negativos: censuran y limitan el alcance del Banquete plutarqueo. Señalan la falta de inventiva, el estigma de lo inacabado y el exceso de licencias literarias, de artificio.

Mi objetivo, no obstante, es analizar este tratado precisamente a través de su manifiesto carácter escolar y la luz que arroja en el periodo de formación de su autor, acaso el más arduo y laborioso, aquel en que se escogen y ensayan varios caminos y también aquel en que se descubren los territorios y vados que tan sólo conviene mirar desde las orillas. Sobre todo, si aceptamos que la fecha asignada a esta obra en la carrera de Plutarco apunta aún a su etapa de formación ${ }^{6}$. Clasificando esta obra como un ejercicio escolar apreciaríamos mejor y seríamos más condescendientes con su temeraria invención y con el deliberado anacronismo que la permea, al tiempo que nos entregaría los trazos inestables de todo empeño por adquirir un estilo propio.

2. Cuando se habla de ejercicio escolar hemos de referirnos obligadamente a uno de los métodos más productivos en la época imperial para el aprendizaje gradual de la retórica y de sus formas discursivas fundamentales: los progymnásmata o ejercicios de preparación, cuya formulación, esquematización e incluso ejemplificación nos legaron Teón de Alejandría, Hermógenes de Tarso, Aftonio de Antioquía y Nicolás de $\mathrm{Mira}^{7}$, por mencionar tan sólo los manuales griegos que nos han sobrevivido y que datan del siglo I al $\mathrm{V}$ d.C ${ }^{8}$. Que Plutarco se aplicara a su estudio y laboriosa asimilación nos explica en parte que dos ejercicios constituyan las líneas directrices de su trabajo literario: por una parte, la synkrisis vertebra el plan biográfico de las Vidas paralelas, así como por la otra la profusa producción "chreica" recorre sus Ensayos misceláneos $y$ cartas, como quería Babbitt que tituláramos sus tratados morales ${ }^{10}$.

Apoyándonos tan sólo en el vínculo temporal, que haría factible el textual

Griechenland, Lemgo, 1781, I, p. 135 sqq., seguido por R. Volkmann, 1967, posturas finalmente adoptadas por las historias de la literatura griega de W. Christ, 1889 y M. Croiset, 1928.

${ }^{5}$ Según la síntesis de las posturas críticas ante el tratado que, en su edición, hace J. Defradas, 1985, p. 171: “Ce recueil de platitudes ne pourrait être l'œuvre de l'auteur des Moralia: ce ne serait qu'un travail scolaire écrit par un sophiste contemporain”.

${ }^{6}$ J. Sirinelli, 2000, p. 160: "On peut discuter à l'infini sur la date du Banquet. Aucun argument n'est déterminant, les allusions à la démocratie pas plus que les autres. On doit songer plutôt à un exercice un peu artificiel des années d'enseignement, entre 80 et 90 ou même 95 ”.

${ }^{7}$ Cf. M. Patillon \& G. Bolognesi, 1997; G. A. Kennedy, 2003. La traducción de los progymnasmata citada en este trabajo es la de M. D. Reche Martínez, 1991.

${ }^{8}$ Sobre la versión latina de los progymnásmata cf. S. F. Bonner, 1977, pp. 250-76. Para la época bizantina cf. H. Hunger, 1978, pp. 92-120. Análisis de la obra de Plutarco a la luz de la teoría progimnasmática han sido llevados también a cabo por J. A. Fernández Delgado, 2000; y por A. Vicente, 2005; y, eadem, en este mismo volumen, pp. 75-85.

${ }_{9}^{9}$ P. Hirzel, 1963, p. 142 afirma que la intención de Plutarco era hacer una colección de chreiai en forma de banquete: "Man hat den Eindruck, dass es ihm hauptsächlich darauf ankam eine Chriensammlung in die Form eines Symposions zu bringen (vgl. o.S. 115,1) und dann mit allen Farben der Rhetorik auszumalen".

${ }^{10}$ F. C. Ваввіт, 1949, p. xiii: "Certainly a better descriptive title would be "Miscellaneous Essays and Letters", for the Moralia cover many fields, and show an astounding learning and a wide range of interests". 
e incluso el espacial -la historia literaria hace converger a ambos autores en el siglo I d.C. -, y ante el desconocimiento del rétor que marcó la actividad libresca del Queronense ${ }^{11}$, conjeturemos una posible relación magisterial entre Teón de Alejandría y Plutarco, y veamos cómo llegó a reflejarse en la obra que nos ocupa.

3. No hay nada equiparable, nos dice Jean Sirinelli ${ }^{12}$, a excepción del Gryllos, en el corpus plutarqueo, en lo que respecta a la introducción de personajes abierta y totalmente ficticios, al Septem sapientium convivium. ¿Por qué Plutarco optó por hacer un simposio y por qué escogió entre los comensales al oscilante grupo de los Siete Sabios?

Tal vez en principio asumió la exigencia subrayada por Teón de no acercarse a ninguna modalidad oratoria sin antes adentrarse en el estudio de la filosofía so pena de perder amplitud de pensamiento ${ }^{13}$. A aquella se

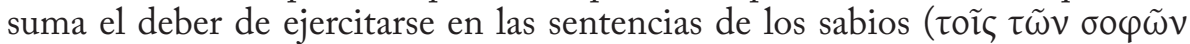
$\alpha \dot{\pi} \sigma \varphi \theta \varepsilon ́ \gamma \mu \alpha \sigma \nu v)$ y recopilarlas de las obras antiguas para adquirir, a fuerza de interiorizarlas, un carácter virtuoso ${ }^{14}$. De ahí que el Queronense se esmerara en la compilación y confección de apotegmas, hypomnemata, chreiai, proverbios y sentencias a las que posteriormente recurrirá para aderezar sus escritos. Baste leer la justificación de sus Regum et imperatorum apophthegmata (172d-e):

En las Vidas, las manifestaciones de los hombres se sitúan junto a sus hechos y aguardan el placer de una lectura sosegada. Aquí, pienso que sus palabras, coleccionadas por separado como ejemplo y semilla de sus vidas ( $\delta \varepsilon \dot{\gamma} \mu \alpha \tau \tau \alpha \tau \tilde{\omega} v$

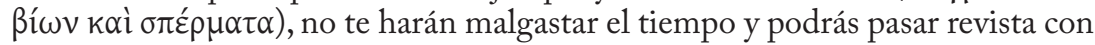
brevedad a muchos hombres dignos de recuerdo ${ }^{15}$.

O baste recordar las líneas donde afirma: "Hice una colección de aquellos

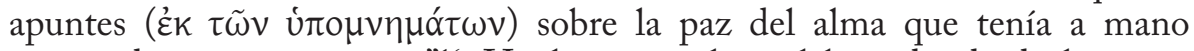
preparados para mí mismo"16. Huelgue citar las palabras donde declara este conveniente hábito: "Por esto intento siempre reunir y releer no ya solamente estos dichos de los filósofos [...] sino más bien los de los reyes y tiranos"17, donde vemos declarada la predilección plutarquea por la sabiduría práctica más que por el conocimiento teórico. No nos extrañe entonces la atención que le merecieron los Sietes Sabios, a quienes los griegos pusieron en el origen de

${ }^{11}$ J. M. Díaz Lavado, 1999, p. 58. En todo caso, de la teoría progimnasmática hay indicios anteriores a Teón, su primer codificador conocido.

12 J. Sirinelli, 2000, p. 161. “...il n'y a guère dans toute l'oeuvre de Plutarque de textes du même ordre; il y a des traités, des dialogues fictifs ou réels entre des personnages réels de l'entourage de Plutarque, des biographies, mais nous n'avons que deux dialogues entre des personnages ouvertement et totalment fictifs, ce sont le Gryllos et le Banquet des sept sages."

${ }^{13}$ Theon $1,1-4$.

${ }^{14}$ Theon 2,16-19.

15 Trad. M. López Salvá \& M. A. Medel, Plutarco. Obras Morales y de Costumbres, III, Madrid, 1987.

${ }^{16}$ Cf. De tranquillitate animi (Mor. 464F) Trad. R. M.a Aguilar, Plutarco. Obras Morales y de Costumbres (Moralia), VII, Madrid, 1995.

${ }^{17}$ Cf. De cohibenda ira (Mor. 457D-E). Trad. R. M. a Aguilar, 1995. 
su historia de la filosofía y de los cuales Heródoto nos ofrece algunos ejemplos de su agudeza política ${ }^{18}$ : "hombres prácticos, de acción -nos dice B. Snell-, que en su mayoría, participaban en la vida del Estado como legisladores, soberanos o consejeros" 19 .

Por lo tanto, Plutarco debió en principio de someterse a la tarea de recoger un corpus de sentencias y consejos útiles comenzando por las inscripciones délficas: "conócete a ti mismo" y "nada en demasía". En el curso de la encuesta se enfrentaría a la falta de acuerdo tanto en la atribución de las sentencias como en el número de los $\mathrm{Sabios}^{20}$, hecho que reflejará y solucionará en la introducción de su Simposio al multiplicar el número de comensales. Importaba más, en cambio, la pervivencia del conocimiento acumulado, que todas las sentencias se acomodasen muy bien a la definición de la chreia del rétor alejandrino; en suma, que fueran declaraciones o acciones breves atribuidas a un personaje determinado y que fueran útiles (chreiai) para la vida ${ }^{21}$. Habría también seguido con atención el ejemplo de chreia verbal de respuesta interrogativa y su alusión a Pítaco de Mitilene ${ }^{22}$.

4. El siguiente paso era encontrar qué tipo de discurso hacer con su acopio de sentencias: ¿cuál era la mejor forma de realizar el exhaustivo programa que Teón presenta para ejercitarse en la chreia, el cual comprende tres géneros ${ }^{23}$, cinco tipos $^{24}$, seis subespecies ${ }^{25}$ y doce categorías formales ${ }^{26}$ ? Plutarco debió de pensar en el recurso de pregunta y respuesta que la primera sofística encontrara $^{27}$ al transitar por el terreno de las antinomias y perfeccionar el arte de hacer prevalecer la opinión personal, cuyo desarrollo culminaría en el diálogo platónico. Esta fase intermedia podemos encontrarla en las respuestas que el rey etíope, referidas por Nilóxeno de Náucratis, da a las preguntas ¿Qué es lo más viejo, lo más hermoso, lo más grande, lo más sabio, lo más común, lo más útil, lo más perjudicial, lo más poderoso y lo más fácil? (Mor. 152E-

${ }^{18}$ Cf. Hdt. I 27, 29, 59, 74 y 170.

${ }^{19}$ El descubrimiento del espiritu (Die Entdeckung des Geistes, trad. J. Fontuberta), Barcelona, 2007 (1 $1^{\mathrm{a}}$ ed. Hamburgo, 1963), p. 504.

${ }^{20}$ D. L. 40-41.

${ }^{21}$ Theon 18, 9-14.

${ }^{22}$ Cf. Theon 20, 3-6: "Habiéndole sido preguntado a Pítaco de Mitilene si la mala conducta pasa desapercibida a los dioses, respondió: 'No, ni aún pretendiéndolo'."

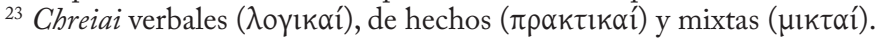

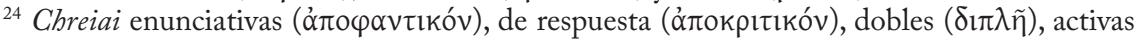

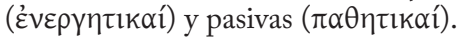

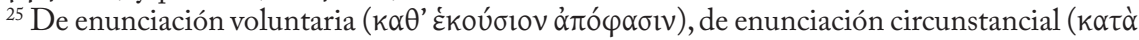
$\pi \varepsilon \rho i ́ \sigma \tau \alpha \sigma l v)$, interrogativas ( $\left.k \alpha \theta^{\prime} \varepsilon \dot{\varepsilon} \rho \omega ́ \tau \eta \sigma \jmath v\right)$, indagativas ( $\left.\kappa \alpha \tau \grave{\alpha} \pi u ́ \sigma \mu \alpha\right)$, causales interrogativas

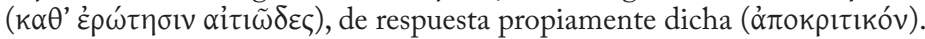

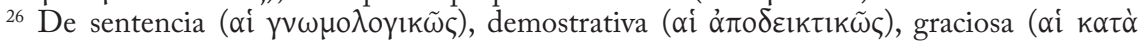

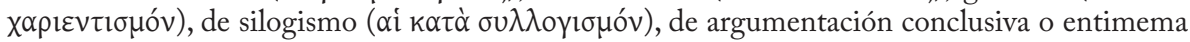

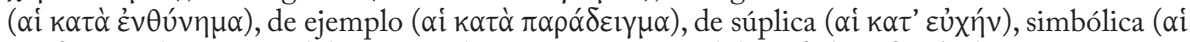

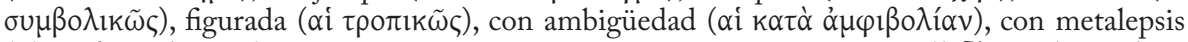

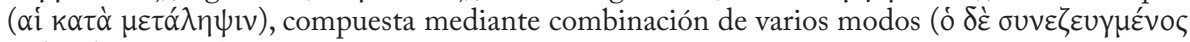

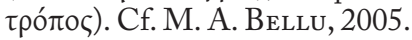

${ }^{27}$ D. L. 9 53-55 nos dice que Protágoras fue el primero en suscitar el modo de dialogar que

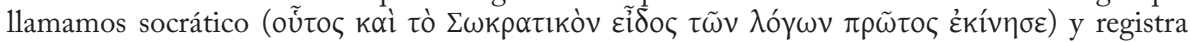
entre sus libros una Técnica de controversias ( $\tau \dot{\chi} \chi \vee \eta ~ \varepsilon ́ p ı \sigma \tau 1 \kappa \tilde{\omega} v)$. 
153A), preguntas ipso facto refutadas por Tales de Mileto (Mor. 153B-C), en una escena que refleja muy bien el juego sofístico de hacer preguntas que expresasen el grado máximo de una cualidad o de una circunstancia.

La elección de esta forma literaria parecía ineluctable. Unos supuestos Septem sapientium logoi debían aspirar a ocupar un lugar junto a los logoi socráticos del autor que llevara este género a la perfección y a quien Teón recurría constantemente como modelo ya no sólo del progimnasma de la chreia sino de otros más: de la fábula, el relato mítico ${ }^{28}$, la descripción ${ }^{29}$, la caracterización $^{30}$ y el encomio ${ }^{31}$. A Plutarco quizá lo animó el hecho de que sólo Jenofonte, otro escritor ecléctico, hubiera tratado de emular los diálogos platónicos sin transigir en la caricatura. Después de todo, a pesar de que los Memorabilia fueron redactados transcurridos casi sesenta años después de la muerte de Sócrates, existe la tesis, sustentada por O. Gigon ${ }^{32}$, de que Jenofonte se había remontado a una extensa literatura socrática, no dependiente de la de Platón y más antigua, de mentalidad más simple.

Plutarco había remontado no años sino épocas enteras para espigar una literatura igual de extensa y hacerse con un catálogo de las sentencias de los sabios. Tenía la forma en que debía integrarlas, el diálogo simposiaco, y con ésta resolvía la construcción escénica y la inserción de cuadros ricos en polémicas. El Queronense, no apartándose del patrón platónico, hace contar a uno, Diocles, a manera de refutación de una apócrifa versión en boga, lo narrado por un tercero ausente y traslada la escena a un pasado remoto. Tenía a los personajes. Quedaba por revestir las conversaciones de sus personajes de naturalidad y encanto, dotarlas de animación.

Para tal empresa recurrió al progimnasma de la caracterización o prosopopeya. Teón la había definido como "la introducción de un personaje que pronuncia discursos indiscutiblemente apropiados a su propia persona y a las circunstancias en que se encuentra" ${ }^{33}$. En este caso Plutarco ya sabía qué diría cada personaje, sólo restaba concebir las circunstancias. Más allá de la general, el banquete organizado por Periandro en la fiesta sacrificial en honor de Afrodita (Mor. 146C-D), hacía falta la pauta para que las sentencias aparecieran con cierta espontaneidad en el texto.

Jean Defradas ha señalado que el desorden de la composición es el defecto

${ }^{28}$ Theon 10, 2-7: "De narración serían ejemplos hermosísimos, de las míticas, la de Platón en el libro segundo de la República sobre el anillo de Giges y en el Banquete sobre el nacimiento del amor, así como las relativas a los temas del Hades presentes en el Fedón y en el libro décimo de la República."

29 Theon 12, 8-13: "Muchas descripciones han sido realizadas por los antiguos, como en Tucídides, en el libro segundo, la peste y, en el tercero, el cerco de Platea y, en otra parte, un combate naval y un combate a caballo; y en Platón, en el Timeo, lo relacionado con Sais...”.

${ }^{30}$ Theon 12, 23-26: "De prosopopeya ¿qué ejemplo habría más hermoso que la poesía de Homero, los diálogos de Platón y de los demás socráticos, y los dramas de Menandro?”. Platón..."

31 Theon 12, 26-13,1 "Tenemos también los encomios de Isócrates, los epitafios de

${ }^{32}$ O. Gigon, Sokrates: sein Bild in Dichtung und Geschichte, 1947, p. 525.

${ }^{33}$ Theon 70,1-3. Los otros manuales designan de ordinario a este ejercicio con el término etopeya. 
principal de este banquete y que todo intento por encontrarle una unidad resulta vano ${ }^{34}$. Sin caer en la excesiva generalización con que E. David fijó el tema central: "la vida social en su aspecto más general y más particular" 35 , bien podemos desdoblarlo un poco y establecerlo de la siguiente manera: un examen del vicio y la virtud a partir de los cuatro ámbitos característicos de acción humana: el simposiaco, el doméstico, el político y el religioso ${ }^{36}$. Semejantes ámbitos servirían a Plutarco para articular sus catálogos chreicos con las virtudes y vicios típicos de cada uno de ellos.

Plutarco y Teón comparten el mismo interés en la formación moral sin por ello descartar en su exposición y pedagogía los casos escabrosos: "Es necesario -nos dice Teón- cuidar no menos el decoro, de manera que no pongamos al descubierto lo vergonzoso directamente, sino que lo expongamos mediante circunloquios" 37 . Con esta pauta vemos cómo el rétor alejandrino ${ }^{38}$ transcribe un ejemplo de chreia lleno de picardía sacado de la República 329b-c:

-Sófocles, ¿qué tal estás para los placeres del amor?

- ¡Calla la boca -responde [Sófocles] -, pues yo con la mayor alegría huí de ellos como si escapase de un amo furioso y cruel.

Con esta misma pauta vemos cómo el polígrafo queronense hace que Tales aligere el funesto presagio del nacimiento de un centauro, calificado por Periandro como una infamia y una impureza, y que el de Mileto zanja con una

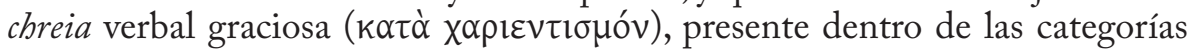
formales del ejercicio: "No emplees a hombres tan jóvenes para cuidar tus caballos, o proporciónales mujeres" (Mor. 149E). La pulla va dirigida contra Diocles, nuestro cronista del Banquete, adivino de la corte de Periandro, y según David E. Aune ${ }^{39}$, pseudónimo bajo el que se agazapa Plutarco. Asentimos si pensamos que la alusión a unos aparentemente absurdos ritos de purificación va dirigida al pepaideumenos, al lector familiarizado con Heródoto o con la noticia que él registra, de que el presagio de querella y discordia tuvo repercusiones más graves que la simple negativa de Alexídemo a comer con los Sabios ${ }^{40}$. Pero si esta chreia presenta algo gracioso ${ }^{41}$ sin que aporte ninguna utilidad vital, vayamos ahora como quiere Teón a las sentencias que se refieren a las cosas útiles para la vida ${ }^{42}$ y demostremos con más ejemplos concretos cuán

${ }^{34}$ J. Defradas, 1985 , p. 173.

35 E. David, 1936.

${ }^{36}$ En la actualidad, el filósofo holandés R. Riemen dirá, de la mano de Thomas Mann, que el arte, la moral y la política conforman la totalidad de la vida humana. Cf. R. Riemen, 2008.

${ }^{37}$ Theon $16,25-26 ; 17,1$

${ }^{38}$ Theon $9,13-20$.

${ }^{39}$ In H. Betz (ed.), 1978, p. 51.

${ }^{40}$ Hdt. III 50-53.

${ }^{41}$ En todo caso, el humor es un componente importante del material progimnasmático. Cf. J. A. Fernández Delgado, 1996.

${ }^{42}$ Theon 19, 5-8: Se le llama chría por excelencia porque en muchos aspectos es más útil para la vida que las otras formas [sentencia, apomnemoneuma]. 
meticulosamente las categorías formales del rétor se reflejan en el Banquete de acuerdo con los grupos temáticos antes mencionados.

5. Limitemos nuestra investigación, ajustándonos al título de este congreso, al núcleo de acción simposiaca. ¿Qué es lo apropiado a personas que se dirigen al banquete? Tales refiere la anécdota, a manera de ejemplo ( $\kappa \alpha \tau \grave{\alpha} \pi \alpha \rho \alpha ́ \delta \varepsilon \varepsilon \gamma \mu \alpha)$ que posteriormente refutará a partir del argumento ético de la inconveniencia

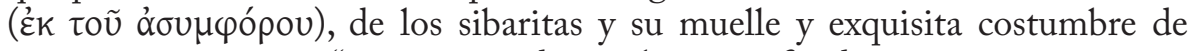
invitar a sus mujeres "con un año de antelación, a fin de que tuvieran tiempo de preparar sus vestidos y adornos para ir al banquete" (Mor. 147E). A Tales, por el contrario, le parece poco tiempo si se trata de adornar el carácter (

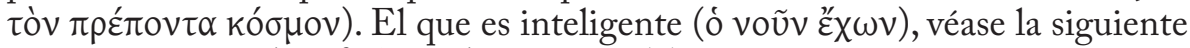
chreia simbólica ( $\sigma u \mu \beta 0 \lambda \imath \kappa \tilde{\omega} \varsigma)$, continúa Tales, no se encamina al banquete como si fuera un vaso vacío dispuesto a ser llenado, imagen que enriquecerá más tarde en sus Quaestiones convivales (Mor. 660A-C). Incluye después una

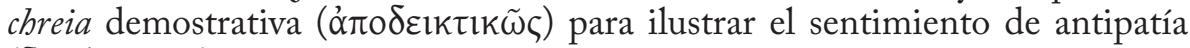

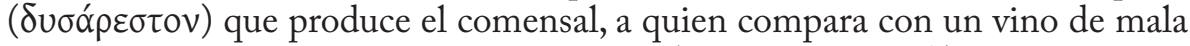
calidad, insolente y grosero en el banquete (Mor. 147F-148A). Más adelante, ahondando en la misma idea, Tales concuerda con el parecer del lacedemonio Quilón, quien rehusaba asistir a un banquete si desconocía la lista de convidados,

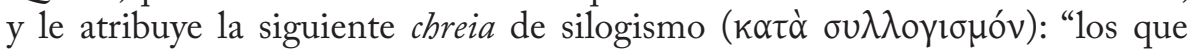
están obligados a navegar o hacer la guerra tienen que soportar al compañero de navegación o de campaña insensato; pero es propio de un hombre poco inteligente aceptar compartir el banquete con unos comensales elegidos al azar" (Mor. 148A). Para finalizar el primer cerco de chreias circunscritas al ámbito simposiaco, Tales nos presenta una de argumentación, naturalmente, conclusiva

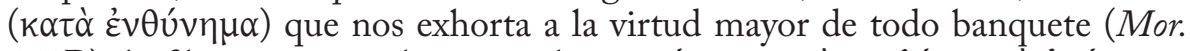

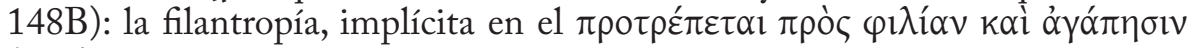
$\dot{\alpha} \lambda \lambda \hat{\eta} \lambda \omega \nu$, curiosamente a través de la tremebunda costumbre egipcia, a caballo entre el respice finem y el carpe diem, de sentar a la muerte en la mesa. Nos dice Plutarco por boca de Tales:

La momia, que los egipcios solían, con buen juicio, colocar y mostrar a los comensales en los banquetes para recordarles que pronto ellos serían como ella, a pesar de que llega como un invitado desagradable e intempestivo, sin embargo aporta alguna ventaja si impulsa a los comensales no a la bebida y al placer, sino a la amistad y al afecto mutuo y los exhorta a no hacer una vida, que es muy corta por el tiempo, larga por sus malas acciones.

(Mor. 148A-B)

El siguiente cuadro continúa no sólo con la lograda caracterización del personaje de Tales sino con la exploración mediante chreias, de otros aspectos morales relativos al simposio. Vemos la animada escena donde el milesio Alexímeno sale furioso del banquete a causa del lugar deshonroso que le asignó Periandro. Nos encontramos ante la versión grecolatina del asunto protocolario de los primeros puestos. Pensemos que la versión judeocristiana, el Evangelio 
de Lucas $(14,7-11)$, se adentra en el mismo asunto también a través de una chreia para amonestar a los invitados que escogen los lugares principales ${ }^{43}$. En nuestra obra, Tales rememora la regia y elegante postura que asumiera

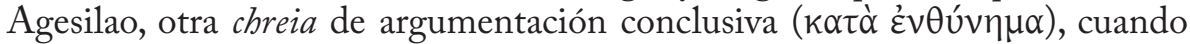
lo relegaron al último lugar del coro y respondiera: "Muy bien, has encontrado cómo convertir este lugar en un sitio honroso" (Mor. 149A). Aderezada con la mención de un ejemplo astrológico y cerrándola con la exigencia de mantener, sea cual sea el lugar que ocupemos, una actitud filantrópica; es decir, buscando

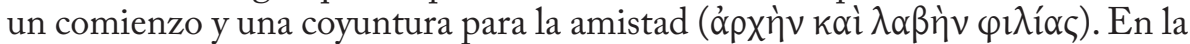
siguiente escena, Tales de Mileto cumplirá con hechos sus palabras, ocupando de buen grado el lugar que despreciara Alexídemo junto al flautista Árdalo de Trecén (Mor. 149F).

Con estos breves ejemplos espero haber demostrado en parte el rigor con que Plutarco ensayó los distintos tipos de chreia pacientemente esquematizados por Teón, y cómo encontró en la forma del diálogo la manera más eficaz de inyectarles vida y llevar a buen término este auténtico tour de force escolar.

\section{Bibliografía CITADA}

Aguilar Fernández, R. M., Plutarco. Obras Morales y de Costumbres, VII, Madrid, 1995.

Aune, D. E., "Septem sapientium convivium”, in H. D. Betz (ed.), Plutarch's Ethical Writings and Early Christian Literature, Leiden, 1978, pp. 51105.

Babвitt, F. C. (ed.), Plutarch's Moralia, I, London/Cambridge, Mass., 1949. Plutarch's Moralia, II, London-Cambridge, Mass., 1956.

Bellu, M. A., La chreia en los Moralia de Plutarco, Tesis Doctoral, Universidad de Salamanca, 2005.

Bonner, S. F., Education in Ancient Rome: From the Elder Cato to the Younger Pliny, Berkeley, 1977.

Christ, W., Geschichte der griechischen Literatur, München, 1898. (1ª ed. Nördlingen, 1889).

Croiset, A. \& Croiset, M., Histoire de la Littérature Grecque, V, Paris, 1928.

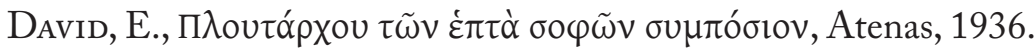

Defradas, J. et al., Plutarque. Oeuvres Morales, II, Paris, 1985.

Díaz Lavado,J.M., Las citas de Homero en Plutarco, Tesis Doctoral,Universidad de Extremadura, 1999.

43 "Porque todo el que se eleva será rebajado y el que se rebaja será ensalzado" (ö

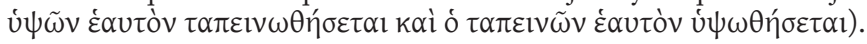


Fernández Delgado, J. A., "El sentido del humor de Plutarco", in J. A. Fernández Delgado \& F. Pordomingo Pardo (eds.), Estudios sobre Plutarco: Aspectos formales, Madrid, 1996, pp. 381-403.

"Le Gryllus, une éthopée parodique", in L. VAN Der StockT (ed.), Rhetorical Theory and Praxis in Plutarch, Louvain-Namur, 2000, pp. 17181.

Gigon, O., Sokrates: sein Bild in Dichtung und Geschichte, Bern, 1947.

Hirzel, P., Der Dialog, II, Hildesheim, 1963 (=Leipzig, 1895).

Hunger, H., Die hochsprachliche profane Literatur der Byzantiner, I, München, 1978.

Kennedy, G. A., Progymnasmata. Greek Textbooks of Prose Composition and Rhetoric (trans., introd. and notes), Leiden, 2003.

López Salvá M. \& Medel, M.A., Plutarco. Obras Morales y de Costumbres, III, Madrid, 1987.

Morales Otal, C. \& García López, J., Plutarco. Obras Morales y de Costumbres, II, Madrid, 1986.

Patillon, M. \& Bolognesi, G. (eds.), Aelius Théon: Progymnasmata, Paris, 1997.

Reche Martínez, M. D., Teón, Hermógenes, Aftonio. Ejercicios de retórica, Madrid, 1991.

Riemen, R., Nobility of Spirit: A Forgotten Ideal, Yale, 2008.

Sirinelli, J., Plutarque de Chéronée. Un philosophe dans le siècle, Paris, 2000.

Snell, B., El descubrimiento del espiritu, Barcelona, 2007. (1ª ed. Hamburg, 1963).

Vicente, A., "Plutarco, Sobre si es más útil el agua o el fuego: Una tesis progymnasmática", in M. Jufresa ET AL. (eds.), Plutarc a la seva época: paideia $i$ societat. Actas del VIII Simposio español sobre Plutarco, Barcelona, 2005, pp. 507-15.

Volkmann, R., Leben und Schriften des Plutarch, Berlin, 1967 (=Leipzig, 1870).

Wyttenbach, D. A., Animadversiones in Plutarchi Moralia, II, Leipzig, 1821. 